\title{
Bipolar TURP decreases post-operative morbidity - A prospective study in a tertiary care hospital from north India
}

\author{
Rajesh Kumar Maurya ${ }^{1}$, Vinay Kumar ${ }^{2}$, Kumar Vineet ${ }^{3}$ \\ ${ }^{1}$ Professor, ${ }^{2}$ Associate Professor, ${ }^{3}$ Resident, Department of General Surgery, GSVM Medical College, Kanpur, Uttar
}

Pradesh, India

Background: Transurethral resection of prostate is considered as gold standard surgical procedure for treatment of benign enlargement of prostate. It can be performed in two forms- monopolar transurethral resection and bipolar transurethral resection. Aims and Objective: This study was conducted to know which energy source among monopolar and bipolar energy leads to more post-operative morbidity after performing transurethral resection of prostate. Materials and Methods: In this study, total eighty (80) cases were included. They were suffering from lower urinary tract symptoms which were diagnosed to be due to benign enlargement of prostate after careful clinical and radiological examination. In forty cases, transurethral resection of prostate was performed by using monopolar energy source and in another forty cases, resection of prostate by transurethral route was done using bipolar energy source. Results: In our study, we found that development of TURP syndrome was more in monopolar TURP group in which pre-operative weight of prostate was more than 50 grams in comparison to bipolar TURP group in which there was no incidence of development of TURP syndrome in same class. Further, post-operative hospital stay and post-operative urethral catheter in situ was less in bipolar TURP group in terms of days as compared to monopolar TURP group. Conclusion: Our study concludes that Bipolar TURP is better in terms of development of less post-operative morbidity as compared to monopolar TURP. Bipolar TURP must be used extensively in teaching hospitals where students take more time than a seasoned surgeon to perform a surgical procedure and bipolar TURP will come handy in that situation.

Keywords: Transurethral resection of prostate (TURP); Monopolar; Bipolar; TUR Syndrome; Saline; Glycine; Prostate

\section{INTRODUCTION}

Benign prostatic hyperplasia (BPH) affects older males. It is a noncancerous increase in size of Prostate. ${ }^{1}$ Symptoms of $\mathrm{BPH}$ is divided into two categories- storage and voiding. Incomplete voiding results in residual urine or urinary stasis, which can lead to an increased risk of urinary tract infection. ${ }^{2}$

Medical management of $\mathrm{BPH}$ is tried in patients having mild to moderate symptoms with drugs like alpha blockers and 5 alpha reductase inhibitors. They provide symptomatic relief to patients along with small reduction in size of prostate. In many patients, despite of showing improvements in lower urinary tract symptoms initially with drugs, and patients with severe BPH symptoms, require surgical intervention. ${ }^{3}$

Before the advent of endoscopic surgeries for BPH, open surgeries were the standard surgical procedure for adenoma. It is performed in different ways and is still practiced in some centers across the world where endoscopic facilities 
are not available. In current time, open surgeries have lowest failure rate among other type of surgeries for $\mathrm{BPH}$ but it brings more morbidity, patient burden and cost. ${ }^{4}$

Though several new procedures such as laser ablation, laser enucleation, photo selective vaporization have been developed for surgery of prostate still transurethral resection of prostate (TURP) is considered most effective and gold standard surgical treatment of BPH. It is performed by visualizing prostate through urethra and cutting prostatic chips using energy sources. ${ }^{5}$ TURP can be performed either by using monopolar energy source or bipolar energy source.

Monopolar energy source uses a wire loop with electrical current flowing through it in single direction. Loop is used to resect prostatic chips. A non-conducting irrigation fluid is required to prevent this current from damaging surrounding tissues along with ESU (Electrostatic systems of units) grounding pad. Bipolar energy source on the other hand uses a conducting fluid such as normal saline for irrigation and also eliminates need for ESU grounding pad. In this there is modified current flow which passes from the resection loop through the conductive irrigation fluid to the metal resection sheath, an additional loop or an extra shackle. Since the impedance of the patient is 10-fold higher than that of the irrigation fluid, the patient no longer constitutes a direct part of the current circle. ${ }^{6}$

Since, Bipolar TURP eliminates need of non-conducting fluid for irrigation, it leads to systemic non-absorption of hypotonic irrigation fluids such as 1.5\% glycine which in turn reduces cases of TUR syndrome. ${ }^{7}$ In cases of monopolar TURP, glycine is the most commonly used irrigation fluid. It is a type of electrolyte free irrigation fluid and its absorption leads to acute hypervolemia and hyponatremia and consequent clinical symptoms described as TUR syndrome. ${ }^{8}$

Many studies which have been done on transurethral resection of prostate in the past but most of the studies did not study effect of weight of pre-operative prostate on development of TUR syndrome. This study is unique in the sense that it further divides each group in the study on the basis of weight of prostate.

\section{Aims and Objectives}

In our study, we compare the post-operative morbidity in terms of development of TUR syndrome, post-operative hospital stay and post-operative urethral catheter in situ between monopolar and bipolar TURP.

\section{Materials and Methods}

This study was conducted over a period of twenty four months (2 years) from October 2018 to September 2020. Cases were admitted with the diagnosis of benign prostatic enlargement from out-patient department (OPD). Patients undergoing TURP were kept in two groups, even number patients in which energy source used was monopolar and odd number patients in which energy source used was bipolar. Eighty (80) symptomatic patients of benign prostatic enlargement were studied. Forty (40) patients were kept in monopolar TURP group and another forty (40) patients were in bipolar TURP group. Out of each forty patients, twenty patients were having prostatic weight between thirty-fifty gram (30-50 gms) and other twenty patients were having prostatic weight ranging between fifty to eighty grams (50-80 gms).

In most of the previous studies which compared development of TUR syndrome in monopolar and bipolar TURP, results were compared between both groups without taking into account the weight of prostate gland. So, we further divided both groups into two classes on basis of weight of prostate (30-50 gms and 50-80 gms).

It is a type of prospective study where intervention is compared between two groups.

All cases taken into study were more than 45 years of age with no co morbidity. Patients with neurovesical dysfunction, bladder calculus, carcinoma prostate, urethral stricture and previous history of prostate or urethral surgery were excluded. Formal written consent was taken from them for participation in study.

Information about volume of irrigant used, type of irrigant used, resection time, weight of gland, changes in hemoglobin concentration, blood sodium and potassium levels were collected.

Bipolar resection was performed using Olympus bipolar resection system and monopolar resection was performed using $\mathrm{L}$ and $\mathrm{T}$ (maestro plus) with cutting and coagulation. Barnes method of resection was used in all our patients. The height of irrigation fluid was standardized to $60 \mathrm{~cm}$. To prevent thermal damage to urethra, copious amounts of jelly around the sheath was used.

When patient attended outpatient department, a careful history of all the symptoms was recorded including age, duration of symptoms, thinning of urinary stream, intermittency, frequency, hesitancy, urgency, nocturia, retention of urine, incomplete emptying, terminal dribbling. Per rectal examination (Digital Rectal Examination, DRE) was done after emptying the bladder to assess the size and nature of prostate enlargement. Supra pubic ultrasonography was used to assess weight and volume of prostate pre operatively along with residual urine volume in all patients. 
Patient was positioned in lithotomy position. Before painting and draping, care is taken to ensure that there is no pressure point under shoulder and knee. Surgery was performed under spinal anesthesia in all patients. Ringer lactate infusion was continued in the intra operative period. $1.5 \%$ glycine was used in Monopolar TURP and normal saline was used for Bipolar TURP.

Bipolar instrument was used for cutting at 160-180W and for coagulation at 90-100W. Similarly, monopolar instrument was used for cutting at 110-160 W and for coagulation at 80-90W.

Continuous post-operative irrigation was done for minimal period of twenty four hours or more as required.

\section{Ethics}

Since study involves human subjects, procedures followed were in accordance with the ethical standards of the responsible committee on human experimentation (institutional). Institutional Ethical Committee approval was taken for this study.

\section{Statistics}

Categorical data was compared by using chi square test and numerical data was compared using unpaired t-test. $\mathrm{t}$ was considered statistically significant at $\mathrm{p}$ value $<0.05$.

\section{RESULTS}

First group $(\mathrm{n}=40)$ underwent TURP performed by monopolar electro cautery using $1.5 \%$ glycine as an irrigant. In second group $(\mathrm{n}=40)$, bipolar energy source was used with $0.9 \%$ saline as irrigate. Weight of prostate gland was between 30-80 grams. There was no statistical significant difference between weights of glands in both groups. It was comparable.Average weight of gland in 30-50 grams class of monopolar and bipolar groups were 39.53 grams and 39.97 grams respectively. Similarly, average weight of gland in 50-80 grams class of monopolar and bipolar groups were 64.05 grams and 64.91 grams respectively.

Post-operative development of TURP syndrome using monopolar TURP and bipolar TURP was compared.

By applying chi-square test in 50-80 gm class, the chi-square statistic is 5.7143 . The p-value is .016827 . The result is significant at $\mathrm{p}<.05$.

Further, post-operative hospital stay was compared between monopolar TURP and bipolar TURP group. For this comparison, classes based on weight of prostate were removed and both groups were compared. It was found out that post-operative hospital stay(in days) was less in patients operated by Bipolar TURP compared to Monopolar TURP and it was statistically significant.

Similarly, comparing post-operative triway catheter in situ (in days) between monopolar TURP and bipolar TURP group, it was concluded that patient operated by bipolar TURP have less post-operative catheterization time as compared to monopolar TURP.

Comparison of resection/cutting time of prostate (time required to cut chips of prostate gland which provides significant improvement in symptoms) with weight of gland using monopolar TURP and bipolar TURP was done. There was no difference in cutting time of prostate when comparison was done between 30-50 gms classes of monopolar TURP and bipolar TURP. In the same way, there was no difference in cutting time between 50-80 gms classes of monopolar TURP and bipolar TURP. The difference was statistically insignificant.

\section{DISCUSSION}

It was observed that in class of 30-50 gms weight, there was no incidence of development of TURP syndrome in Monopolar TURP or Bipolar TURP. But, in class of 50-80 gms weight, there were 5 incidences of development of TURP syndrome out of 20 patients in Monopolar TURP group and there was not a single case of TURP syndrome in Bipolar TURP class of 50-80 gms. Above values indicates that there is no difference in safety profile of Monopolar TURP or Bipolar TURP in 30-50gms class but Bipolar TURP is safer in terms of development of TURP syndrome in 50-80 gms class as compared to Monopolar TURP 50-80 gms class. In a Cochrane review of 59 randomized trials that compared monopolar and bipolar TURP, it was stated that incidence of TURP syndrome is more in monopolar TURP group as compared to bipolar TURP group.?

Patients who were operated by bipolar TURP stayed in hospital for a mean duration of 2.07 days in compared to patients operated by monopolar TURP which stayed for duration of 3.5 days in hospital. The difference in post op hospital stay is statistically significant. It can be bluntly stated that patient operated by Bipolar TURP requires less post-operative hospital stay which in turns leads to less expenditure on account of both patient and hospital. In a study conducted in Japan in past, it was found out that post-operative hospital stay was less in patients undergoing bipolar resection of prostate. ${ }^{10}$ 
In monopolar TURP group, Triway per urethral catheter was-in-situ for a mean period of 6.4 days and in Bipolar TURP group, Triway per urethral catheter was in situ for a mean period of 4.89 days. Difference between both the groups was statistically significant and it can be said that Bipolar TURP leads to less in situ time of Triway catheter which in turn leads to less chances of infection, less morbidity and more freedom for patient. In a study conducted on cases above 75 years of age in China, it was observed that post-operative catheterization of patients were of significantly less duration in bipolar TURP as compared to monopolar TURP. ${ }^{11}$ In a similar study conducted over 100 patients, it was found out that discharging patient on first post-operative day after removing catheter in bipolar TURP have good clinical outcome. $^{12}$

In our study, we also compared cutting time of gland in all the four classes. Mean resection time in 30-50 grams Monopolar TURP group was $44.7 \mathrm{~min}$ in comparison to $43.85 \mathrm{~min}$ in $30-50 \mathrm{gm}$ Bipolar TURP group. Further, mean resection time in 50-80 grams Monopolar TURP is $72.4 \mathrm{~min}$ and $50-80 \mathrm{gm}$ Bipolar TURP is $69.6 \mathrm{~min}$. Though, cutting time in both classes of B-TURP group was slightly less than M-TURP group but no statistical significant difference arise between both groups. Since, patient in both groups were operated by same surgeons, it can be stated that there is no difference in cutting time of gland with respect to weight on the basis of energy sources. A previous study in India, compared above parameter and found that there is no difference in cutting time of prostate between bipolar TURP and monopolarTURP. ${ }^{13}$

In a study conducted in 2016, it was observed that monopolar TURP lead to development of TURP syndrome in $2.06 \%$ of patients but there was not a single case of TURP syndrome in bipolar TURP group. The mean prostate size of patient undergoing monopolar TURP in the study was 38.12 grams and mean prostate size of patient undergoing bipolar TURP was 66.49 grams. This study concluded that bipolar TURP is better than monopolar TURP in terms of development of TURP syndrome and larger prostate glands need to be operated by bipolar TURP. ${ }^{14}$ In our study also we concluded that larger prostate gland should be operated by bipolar TURP but on the basis of observation in our study, we derived a cutoff point of 50 grams of prostatic weight. Prostates having weight more than 50 grams must be operated by bipolar TURP and prostates having weight less than 50 grams can be operated by either monopolar TURP or bipolar TURP if we compare the result in terms of TURP syndrome development.
From the above discussion, it can be concluded that monopolar TURP has risk of development of TURP syndrome in cases with weight of prostate more than $50 \mathrm{gm}$. It can be due to more resection/cutting time of large weight prostate which in turns leads to more absorption of electrolyte free irrigation fluid like glycine. But similar problem was not observed in bipolar TURP because irrigation fluid used was $0.9 \%$ sodium chloride/ normal saline.

In monopolar TURP, energy is directed towards tissues which create resistance and in turn leads to severe increase in temperature. In bipolar TURP, saline irrigate medium is converted into a plasma field of ionized particles by energy which disrupts organic molecular bonds of tissues. Since, directed current from active electrode is returned back by an adjacent return electrode, tissue temperature is reduced which causes minimal collateral tissue damage. ${ }^{15}$ This might be a reason for early discharge of cases from hospital and early removal of urethral catheter.

Early discharge of patient from hospital decreases financial burden both on patient and hospital and also create space for next patient. This is especially helpful in government hospitals where there is always paucity of beds. Also early removal of per urethral catheter provides a sense of freedom to patient. Both of these in a way decrease postoperative morbidity of patient.

The lack of blinding in the treatment arm to the operating surgeon could be a source of bias.

\begin{tabular}{|c|c|c|c|c|}
\hline & \multicolumn{2}{|c|}{ Monopolar group } & \multicolumn{2}{|c|}{ Bipolar group } \\
\hline & $\begin{array}{c}30-50 \mathrm{gm} \\
\mathrm{n}-20\end{array}$ & $\begin{array}{c}50-80 \mathrm{gm} \\
\mathrm{n}-20\end{array}$ & $\begin{array}{c}30-50 \\
\text { gm } \\
n-20\end{array}$ & $\begin{array}{c}50-80 \mathrm{gm} \\
\mathrm{n}-20\end{array}$ \\
\hline $\begin{array}{l}\text { Incidence of } \\
\text { TURP syndrome }\end{array}$ & 0 & 5 & 0 & 0 \\
\hline
\end{tabular}

\begin{tabular}{lll}
\multicolumn{3}{l}{ Table 2:Post-operative hospital stay (in days) } \\
\hline Monopolar group & Bipolar group & Inference \\
\hline $\mathrm{n}-40$ & $\mathrm{n}-40$ & Significant at $\mathrm{p}<0.05$ \\
mean- 3.52 days & mean- 2.07 days & \\
$\mathrm{SD}-1.57$ & SD- 0.86 & \\
\hline
\end{tabular}

\begin{tabular}{lll}
$\begin{array}{l}\text { Table 3:Post-Operative Triway catheter in situ } \\
\text { (in days) }\end{array}$ & \\
\hline Monopolar group & Bipolar group & Inference \\
\hline $\mathrm{n}-40$ & $\mathrm{n}-40$ & Significant at $\mathrm{p}<0.05$ \\
mean- 6.4 days & mean- 4.89 days & \\
SD -1.89 & SD- 1.28 & \\
\hline
\end{tabular}




\section{CONCLUSIONS}

In this study, we found out that Bipolar TURP is better than monopolar TURP in terms of reducing postoperative morbidity of patient. Bipolar TURP decreases post-operative morbidity and chances of developing TURP syndrome in a patient. Prostates of more than 50 grams weight should be operated by bipolar TURP. It is a technique which can be used extensively in teaching hospitals/medical colleges where residents learn surgery and take more time than consultant surgeons to perform a surgery.

\section{ACKNOWLEDGEMENT}

The authors take this opportunity to thank Dr. Avijit Kumar, M.Ch. Urology

\section{REFERENCES}

1. Roehrborn CG. Benign prostatic hyperplasia: an overview. Reviews in urology. 2005; 7 (Suppl 9): S3-S14.

2. Truzzi JCl, Almeida FMR, Nunes EC and Sadi MV. Residual Urinary Volume and Urinary Tract Infection-When are They Linked? Journal of Urology. 2008; 180(1): 182-185.

https://doi.org/10.1016/j.juro.2008.03.044

3 Jiwrajka M, Yaxley W, Ranasinghe S, Perera M, Roberts MJ and Yaxley J. Drugs for benign prostatic hypertrophy. Australian prescriber. 2018; 41(5): 150-153.

https://doi.org/10.18773/austprescr.2018.045

4. Tubaro A and de Nunzio C. The Current Role of Open Surgery in BPH. EAU-EBU Update Series. 2006; 4(5): 191-201.

https://doi.org/10.1016/j.eeus.2006.07.002

5. Rocco B, Albo G, Ferreira RC, Spinelli M, Cozzi G, Dell'orto $P$, et al. Recent advances in the surgical treatment of benign prostatic hyperplasia. Therapeutic advances in urology. 2011; 3(6): 263-272. https://doi.org/10.1177/1756287211426301

6. Bach T, Herrmann TR, Cellarius C, Geavlete B, Gross AJ and Jecy M. Bipolar resection of the bladder and prostate-initial experience with a newly developed regular sized loop resectoscope. Journal of medicine and life. 2009; 2(4):443-446.

7. Issa MM. Technological advances in transurethral resection of the prostate: bipolar versus monopolar TURP. Journal of endourology. 2008; 22(8): 1587-1595.

https://doi.org/10.1089/end.2008.0192

8. Kumar V, Vineet $\mathrm{K}$ and Deb A. TUR syndrome - A report. Urology case reports. 2019; 26: 100982. https://doi.org/10.1016/j. eucr.2019.100982

9. Alexander C, Scullion MMF, Omar M, Yuan Y, Mamoulakis C, N'DowJMO, et al. Bipolar versus monopolar transurethral resection of the prostate for lower urinary tract symptoms secondary to benign prostatic obstruction. Cochrane Database of Systematic Reviews. 2019; Issue 12. Art. No.: CD009629. https://doi.org/10.1002/14651858.CD009629.pub4

10. Sugihara $T$, Yasunaga $H$, Horiguchi $H$, Nakamura $M$, Nishimatsu $H$, Kume $\mathrm{H}$, et al. In-hospital outcomes and cost assessment between bipolar versus monopolar transurethral resection of the prostate. Journal of endourology. 2012; 26(8): 1053-1058. https://doi.org/10.1089/end.2011.0592

11. Yang EJ, Li H, Sun XB, Huang L, Wang L, Gong XX, et al. Bipolar versus monopolar transurethral resection of the prostate for benign prostatic hyperplasia: safe in patients with high surgical risk. Scientific reports. 2016; 6: 21494.

https://doi.org/10.1038/srep21494

12. Shum CF, Mukherjee A and Teo CP. Catheter-free discharge on first postoperative day after bipolar transurethral resection of prostate: clinical outcomes of 100 cases. International journal of urology. 2014; 21(3):313-318.

https://doi.org/10.1111/iju.12246

13. Kumar A, Vasudeva P, Kumar N, Nanda B, Jha SK and Mohanty N. A prospective randomized comparative study of monopolar and bipolar transurethral resection of the prostate and photoselective vaporization of the prostate in patients who present with benign prostatic obstruction: a single center experience. Journal of endourology. 2013; 27(10): 1245-1253. https://doi.org/10.1089/end.2013.0216

14. Pal D, Madduri VS and Bera M. Monopolar versus bipolar transurethral resection of prostate for benign prostatic hyperplasia: Operative outcomes and surgeon preferences, a real-world scenario. Urology Annals. 2016; 8(3): 291. https://doi.org/10.4103/0974-7796.184900

15. Yoon CJ, Kim JY, Moon KH, Jung HC and Park TC. Transurethral resection of the prostate with a bipolar tissue management system compared to conventional monopolarresectoscope: oneyear outcome. Yonsei medical journal 2006; 47(5): 715-720. https://doi.org/10.3349/ymj.2006.47.5.715

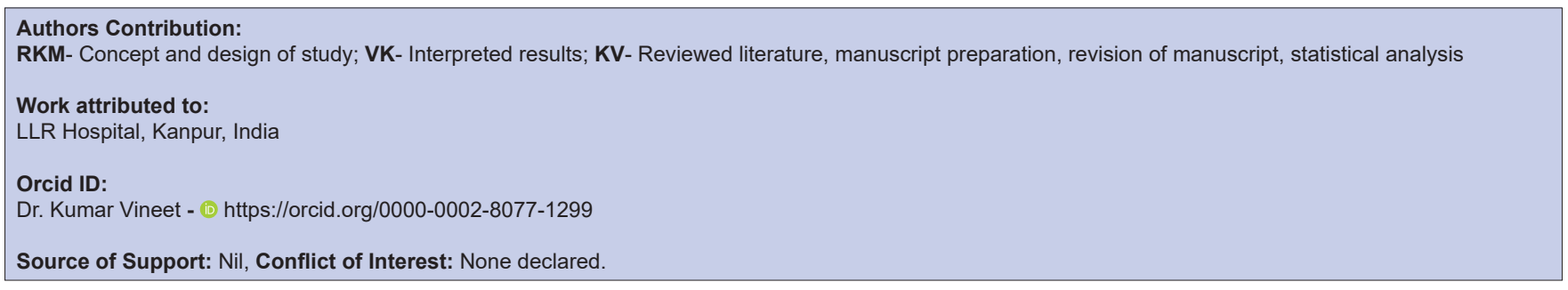

